\section{RUBBER-GLOVE DERMATITIS}

\author{
BY
}

HAROLD T. H. WILSON, M.D., M.R.C.P. Dermatologist, Central Middlesex and Royal Northern Hospitals, London

Eczema of the hands is a chronic condition the aetiology of which is often obscure, the prognosis uncertain, and treatment largely palliative. Some cases, however, can be traced to allergic contact sensitivity, and in these the outlook is greatly improved, for a specific cause may be found and removed.

Downing (1933) reported seven cases of dermatitis of the hands, all attributable to one particular brand of rubber gloves, while other examples were described by Traub (1946) and Bettley (1952). Leider et al. (1952), investigating 124 cases of sensitivity to rubber articles, found that 17 of them were due to gloves, while Sidi and Hincky (1954) were able to collect as many as 102 cases of rubber-glove dermatitis, most of them being caused by red household gloves. Bonnevie and Marcussen (1944) found that allergy to rubber accounted for $2 \%$ of all their cases of sensitivity eczema.

\section{Manufacture of Rubber Gloves}

Rubber occurs in the tree (Hevea brasiliensis) in the form of latex, which is obtained and collected by cutting the bark. In most cases the latex is converted to solid rubber (crêpe or smoked sheet) on the plantation and exported in solid form, but a certain amount of latex is exported in its original liquid state. A preservative (generally ammonia) is added, and the original rubber content (about $40 \%$ ) is increased to $60 \%$ by a concentration process (Stern, 1954).

Whether made from dry rubber or latex, rubber gloves must be vulcanized to acquire typical rubber-like properties. The vulcanization process consists in combining rubber with sulphur. Chemicals known as accelerators are used to speed up this process. Other chemicals used include antioxidants to increase the life of the rubber articles.

Thick gloves, such as those used by electricians, are made from dry rubber. Domestic, surgeons', and other thin gloves are made by dipping a mould either into a solution in a petroleum solvent of the dry rubber or direct into the concentrated latex which has been suitably compounded with the ingredients above mentioned, and also, if necessary, with pigments.

$$
\begin{aligned}
& \text { (1) } \quad \mathrm{H}_{10} \mathrm{C}_{5}=\mathrm{N}-\mathrm{C}-\mathrm{S}-\mathrm{S}-\mathrm{C}-\mathrm{N}=\mathrm{C}_{3} \mathrm{H}_{10} \text { - Dipentamethylene Thiuram Disulphide } \\
& \text { (2) }{ }^{\mathrm{CH}_{3}}>\mathrm{N}-\mathrm{C}-\mathrm{S}-\mathrm{S}-\mathrm{C}-\mathrm{N}^{\prime} \mathrm{CH}_{3} \text {. Tetramethyl Thiuram Disulphide } \\
& \mathrm{CH}_{3} \mathrm{~N}_{\mathrm{S}}^{\mathrm{N}-\mathrm{S}-\mathrm{S}-\mathrm{C}_{\mathrm{S}}-\mathrm{N}^{\prime} \mathrm{CH}_{3}} \cdot \mathrm{CH}_{[\mathrm{MT}]} \\
& \text { (1) } \int_{-\mathrm{S}}^{\mathrm{N}} \mathrm{SC}-\mathrm{SH} \text { Mercoptobenzthiozole } \\
& \text { (2) }{ }_{C_{2} H_{5}}^{C_{2} H_{5}}>N-C_{S}-S-Z_{n}-S-C_{S}-N^{\prime} C_{2} C_{2} H_{5} \text {, Zine Diethyt Dithiocarb mate } \\
& \text { (5) }
\end{aligned}
$$

FIG. 1.-Accelerators commonly used in glove manufacture.
The accelerators used include mercaptobenzthiazole (Fig. 1); thiuram disulphides, such as the dipentamethylene and tetramethyl compounds (P.T.D. and T.M.T.); and dithiocarbamates, such as zinc diethyl, dimethyl, and dibutyl dithiocarbamate.

Antioxidants are not always used with latex, but are generally found in articles made from dry rubber, amine ketone reaction products and substituted phenols being employed for this purpose.

The manufacture of dipped gloves consists essentially in immersing the forma (or mould) into the latex or solution and then drying, vulcanizing, and stripping off the resulting film. The dipping process may be repeated in order to build up a sufficient thickness.

Gloves made from latex are generally leached with water before finally drying and dispatching. This removes soluble products and probably reduces the risk of dermatitis to the wearer. lines.

The compounding of synthetic rubbers follows similar

\section{Investigations}

There were 42 patients in the series, 38 females and 4 males. The age at which sensitivity to rubber first developed ranged from 5 to 77 (Fig. 2), with an average of 47.35 . Of 30 patients who clearly remembered the

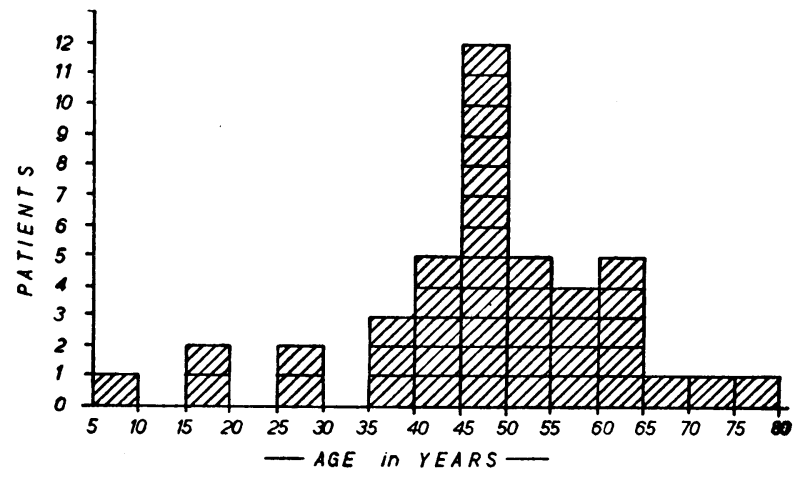

Fị. 2.-Age at onset of sensitivity to rubber.

onset of their rash, 17 had had no skin trouble before wearing gloves, while 13 had started to wear them because they had developed a rash on the hands usually attributed to detergents.

\section{Clinical Features}

The backs of the fingers are usually affected, the backs of the hands, and less commonly the palms. The front, back, and sides of the wrists are often involved, particularly at the point where the top of the glove

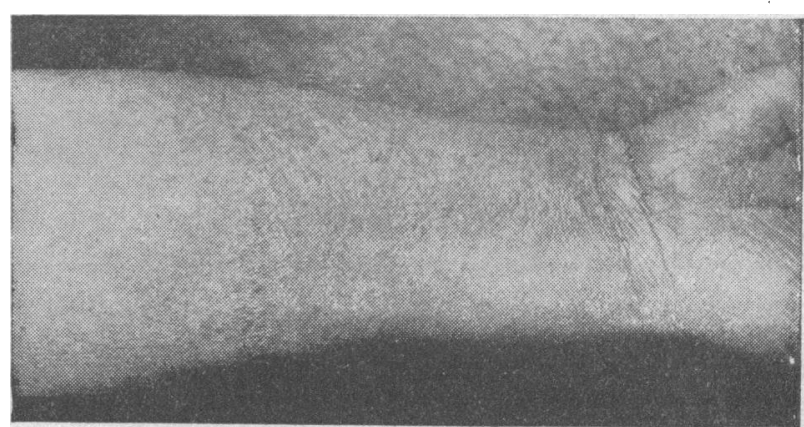

Fig. 3.-Showing the band formed by contact with top of glove. 
comes into contact with the skin (Fig. 3). Here a welldemarcated horizontal band of dermatitis is frequently seen (Fig. 4). This may be joined on the ulnar side by a broader, less well defined band extending along the side of the wrist. These should be looked for in every suspected case of rubber-glove dermatitis, as their presence makes the diagnosis practically certain.

In the early case, recognition is more difficult as the rash may be confined to the back of one hand (usually the right) and a small area at the base of the palmar surface of the thumb (Fig. 5).

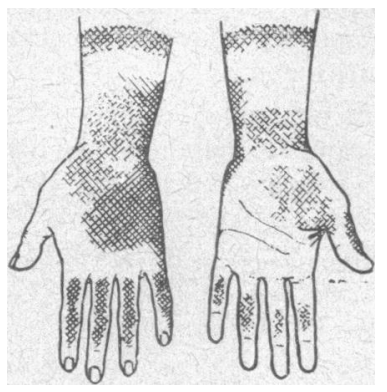

FIG. 4.-Distribution of rubberglove dermatitis.
FIG. 5.-Distribution in an early case.

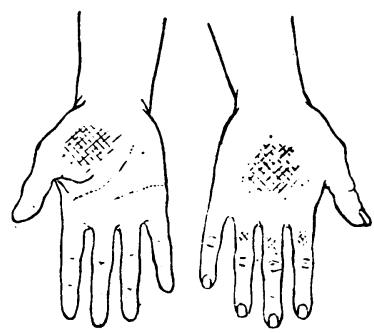

The affected skin is normally reddened and slightly scaling, excoriation marks are common, and vesicles and bullae are comparatively rare.

Other Sites Affected.-Twenty-two patients had suffered from an eczematous rash on other parts of the body. Corsets, or the elastic of brassières or suspenders, accounted for most of these cases (Table I), while several others were attributable to plimsolls or shoes with a rubber insole. Two patients could not tolerate adhesive plaster, and two others developed an acute dermatitis of the face after blowing up balloons. The

TABLE I.-Other Sites Affected

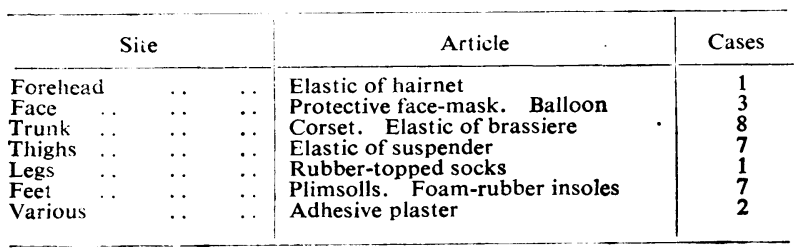

elastic band round a hairnet, elastic-topped socks, and a protective mask used at work were the cause of a rash in three other cases.

Surgical gloves appeared much less likely to sensitize, and 35 tests gave only four positive reactions.

\section{Patch Tests}

When the investigation began, patch tests were performed with a single piece cut from a red rubber glove kept for the purpose. In time it became obvious that this was not a reliable test of rubber sensitivity.

After this experience patients were tested not only against samples of household and surgical gloves but also against their own gloves whenever these could be obtained. A square of rubber approximately $1 \mathrm{~cm}$. in diameter was used. In addition they were tested against the accelerators mercaptobenzthiazole (M.B.T.), dipentamethylene thiuram disulphide (P.T.D.), tetramethyl thiuram disulphide (T.M.T), zinc diethyl dithiocarbamate (Z.D.C.), and 2,2'-methylene-bis

\begin{tabular}{|c|c|c|c|c|c|c|c|c|}
\hline \multirow{2}{*}{$\begin{array}{l}\text { Case } \\
\text { No. }\end{array}$} & \multicolumn{2}{|c|}{ Gloves } & \multirow[b]{2}{*}{ M.B.T. } & \multirow[b]{2}{*}{ T.M.T. } & \multirow[b]{2}{*}{ P.T.D. } & \multirow[b]{2}{*}{ P.B.T. } & \multirow[b]{2}{*}{ Z.D.C. } & \multirow[b]{2}{*}{ A. $K$} \\
\hline & $\begin{array}{c}\text { House- } \\
\text { hoold }\end{array}$ & $\begin{array}{l}\text { Sur- } \\
\text { gical }\end{array}$ & & & & & & \\
\hline 1 & + & - & - & + & + & - & - & - \\
\hline 2 & + & - & + & + & $\frac{1}{4}$ & \pm & - & $\overline{-}$ \\
\hline 4 & $\bar{t}$ & $\overline{-}$ & $\overline{+}$ & \pm & + & $\overline{-}$ & $\bar{z}$ & $=$ \\
\hline $\begin{array}{l}5 \\
6\end{array}$ & + & $\bar{t}$ & $\bar{t}$ & \pm & \pm & $z$ & $\bar{z}$ & 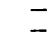 \\
\hline 7 & + & 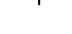 & - & + & + & - & - & - \\
\hline $\begin{array}{l}8 \\
9\end{array}$ & \pm & $\bar{z}$ & - & $\bar{z}$ & $\stackrel{+}{+}$ & $\bar{z}$ & \pm & $\bar{z}$ \\
\hline 10 & + & - & + & - & - & - & - & - \\
\hline $\begin{array}{l}11 \\
12\end{array}$ & $\stackrel{+}{+}$ & $\overline{-}$ & $\bar{t}$ & \pm & \pm & $=$ & $\overline{-}$ & $\bar{z}$ \\
\hline 13 & + & $=$ & \pm & - & - & I & $=$ & - \\
\hline $\begin{array}{l}14 \\
15\end{array}$ & + & - & + & + & \pm & $=$ & $=$ & $\overline{-}$ \\
\hline 16 & + & - & \pm & + & $\dot{t}$ & $\bar{z}$ & $\bar{z}$ & $\overline{-}$ \\
\hline 18 & + & - & + & - & - & - & - & - \\
\hline $\begin{array}{l}19 \\
20\end{array}$ & $\stackrel{+}{+}$ & $z$ & $z$ & $\overline{-}$ & $\stackrel{+}{+}$ & $\overline{-}$ & $=$ & $\overline{-}$ \\
\hline 21 & + & - & - & - & + & - & - & - \\
\hline 23 & \pm & $=$ & \pm & $\bar{t}$ & $\bar{t}$ & $=$ & 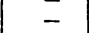 & - \\
\hline 24 & \pm & - & \pm & $\bar{z}$ & \pm & - & $=$ & $\bar{z}$ \\
\hline 26 & + & & - & $\overline{-}$ & $\stackrel{+}{+}$ & - & - & - \\
\hline 27 & \pm & ( & $\overline{-}$ & $\stackrel{+}{+}$ & $\stackrel{+}{+}$ & $\bar{z}$ & $\bar{z}$ & - \\
\hline 29 & + & - & - & + & + & - & - & - \\
\hline $\begin{array}{l}30 \\
31\end{array}$ & $\begin{array}{l}+ \\
+\end{array}$ & $\bar{t}$ & $\begin{array}{l}+ \\
+\end{array}$ & + & $\bar{z}$ & $=$ & $=$ & $\overline{-}$ \\
\hline 32 & + & 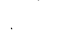 & - & - & - & $=$ & $=$ & 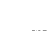 \\
\hline 34 & $\begin{array}{l}+ \\
+\end{array}$ & $=$ & $=$ & + & $\stackrel{+}{+}$ & $\overline{-}$ & $\bar{t}$ & $\bar{z}$ \\
\hline 35 & \pm & $\bar{z}$ & \pm & - & $\bar{\mp}$ & $=$ & $=$ & $\overline{-}$ \\
\hline 37 & + & - & - & $\overline{-}$ & + & - & - & - \\
\hline $\begin{array}{l}38 \\
39\end{array}$ & \pm & $\bar{z}$ & $\bar{t}$ & + & + & $\bar{z}$ & $\bar{z}$ & - \\
\hline 40 & + & \pm & - & - & 4 & - & - & \\
\hline $\begin{array}{l}41 \\
42\end{array}$ & + & & $\overline{-}$ & $\overline{-}$ & \pm & $=$ & $\bar{z}$ & - \\
\hline $\begin{array}{l}\text { Total } \\
\text { tests }\end{array}$ & 42 & 35 & 42 & 42 & 42 & 41 & 42 & 37 \\
\hline+ & 37 & 4 & 15 & 20 & 30 & 1 & 2 & 0 \\
\hline$\%$ & 88.1 & $11 \cdot 4 \hat{j}$ & $35 \cdot 71$ & $47 \cdot 62$ & $71 \cdot 43$ & $2 \cdot 44$ & 4.76 & 0 \\
\hline
\end{tabular}

(4-methyl-6-terbutyl phenol) (P.B.T.). Tests were also performed against an amine-ketone reaction powder (A.K.) used as an antioxidant. All these substances were used in a $1 \%$ dilution in soft paraffin. To avoid contamination they were transferred to the skin on the end of an orange stick, which was not used again. In addition, 31 patients were tested against monobenzyl ether of hydroquinone, which is used in the United States as an antioxidant under the name of agerite alba. Twenty-five patients were also tested against untreated latex.

Patch tests were read after 48 hours and again five or seven days after removal of the patches. After a few days' interval doubtful reactions were found to have faded (when they were regarded as negative) or to have become obviously positive.

\section{Results of Patch Tests}

When tested against household gloves, 37 patients gave positive and five gave negative reactions. Twentyfour patients were tested against their own gloves and a red household glove kept in the department for the purpose. Seven gave positive and five gave negative reactions to both specimens, while 12 gave a positive reaction to their own glove and a doubtful or negative one to the hospital glove.

All but two patients gave positive reactions to one or more of the accelerators against which they were tested. Forty-two tests against P.T.D. gave 30 positive reactions $(71.43 \%)$ and against T.M.T. 20 positive reactions 


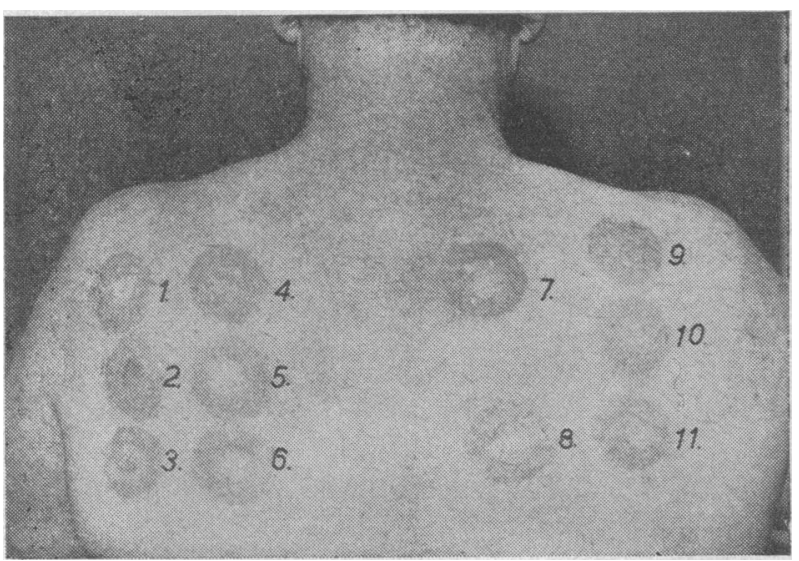

FIG. 6.-Case 14. Patch tests. Positive: P.T.D. (2); T.M.T. (3); own household glove (9). Negative: P.B.T. (1); Z.D.C. (4); M.B.T. (5); A.K. (6); hydroquinone (7); latex (8); hospital glove (10); surgical glove (11).

(47.62\%). Against M.B.T. 42 tests gave 15 positive reactions $(35.71 \%)$. Seventeen patients gave positive reactions to both P.T.D. and T.M.T. (Fig. 6), while 8 reacted to both M.B.T. and either P.T.D. or T.M.T. Only 2 out of 42 patients gave positive reactions to Z.D.C. Of 42 tests against P.B.T. there was only one positive reaction. Patients giving positive reactions to these substances also reacted to P.T.D., T.M.T., or M.B.T. Two patients gave positive reactions to their gloves but negative reactions to all the accelerators.

Twenty-five tests against untreated latex and 37 against the A.K. reaction powder were all negative.

\section{Prognosis}

Eczema or dermatitis of the hands is often slow to heal, and the rash did not invariably clear up as soon as the rubber gloves were discarded; a rapid improvement was, however, seen in nearly every case. when a questionary was sent to 27 patients who had been seen at least six months previously, 17 stated that the rash was cured and the remaining 10 that it had improved since they discarded their rubber gloves.

\section{- Discussion}

The clinical picture of glove dermatitis is usually characteristic, but not invariably so, and patch tests should be done in every suspected case. Tests to glove material were not always reliable, and both false. positive and false-negative reactions were seen. Sidi and Huerre (1952) believe that all cases are not due to accelerators, and two patients in the present series gave positive reactions to their gloves but did not react to any of the accelerators against which they were tested. The remaining 40 reacted to one or more of the accelerators, sensitivity to P.T.D. being found in $71.43 \%$ of cases and to T.M.T. and M.B.T. in $47.62 \%$ and $35.71 \%$ respectively. It was felt, therefore, that tests against these accelerators were more reliable as evidence of rubber sensitivity than tests with patches of rubber glove, though the patient's own glove was more likely to give a positive reaction than a specimen glove which had been kept in the out-patient department for patch-testing. It has been suggested (Anderson, 1944) that patch tests may be positive on the backs of the hands but negative elsewhere. Generally speaking, however, sensitivity is not localized but rapidly spreads over the whole skin.

Vulcanization may continue at a slow rate for some weeks after manufacture, so that the longer the glove is kept the less amount of free accelerator is likely to remain on the surface. The products of the larger manufacturers are likely to be stored for about three months before reaching the shops, a fact which probably reduces the risk of their giving rise to dermatitis. Many of the antioxidants used in rubber manufacture possess both irritant and sensitizing properties (Mallette and Von Haam, 1952), and monobenzyl ether of hydroquinone is a common cause of rubber dermatitis in the United States (Blank and Miller, 1952; Gaul, 1957). It is, however, seldom used in this country as an antioxidant, and there were no positive reactions to it in the present series, nor to the amine-ketone reaction powder A.K. Untreated rubber latex appeared harmless and also gave no positive reactions in the present series, though it has been suggested (Sidi and Huerre, 1952; Thulliez, 1958) that some cases of dermatitis are due to sensitivity to the rubber itself.

Sensitivity to gloves may complicate an idiopathic eczema of the hands or a detergent dermatitis, and 13 out of 30 patients in the present series wore gloves because they had developed a rash on the hands. Gloves made from polyvinyl chloride are unlikely to sensitize, and should be worn in preference to rubber when the skin of the hands is inflamed.

\section{Summary}

Forty-two cases of rubber-glove dermatitis are described. The pattern of the rash is usually characteristic, but not invariably so. Untreated rubber latex appeared harmless, and in 40 cases dermatitis was due to accelerators, usually thiuram compounds or mercaptobenzthiazole. Patch tests with these chemicals were more reliable than tests with rubber material.

In two cases the cause of the dermatitis was unexplained. Thirteen out of 30 cases had a pre-existing hand eczema.

I am indebted to Dr. H. J. Stern for his advice regarding the chemistry of rubber and for supplying the formulae in Fig. 1, and to Mr. R. J. Reid, of the London Rubber Company, for information about the manufacture of rubber gloves. I am also indebted to Dr. F. R. Bettley and Dr. C. D. Calnan for permission to study their cases, and to the medical artist and photographic department of the Central Middlesex Hospital for assistance with the illustrations.

\section{REFERENCES}

Anderson, C. R. (1944). Calif. west. Med., 61, 65. Bettley, F. R. (1952). Proc. roy. Soc. Med., 45, 491. Blank, I. H., and Miller, O. G. (1952). J. Amer. med. Ass., 149. 1371 .

Bonnevie, P., and Marcussen, P. V. (1944). Acta derm.-venereol. (Stockh.), 25, 163.

Downing, J. G. (1933). New Engl. J. Med., 208, 196.

Gaul, L. E. (1957). J. invest. Derm., 29, 105.

Leider, M., Furman, D., and Fisher, A. A. (1952). A.M.A. Arch. Derm. Syph., 65, 587.

Mallette, F. S., and Von Haam, E. (1952). A.M.A. Arch. industr. Hyg., 5, 311.

Sidi, E., and Hincky, M. (1954). Presse méd., 62, 1305.

- and Huerre, J. (1952). Sem. Hôp. Paris, 28, 692.

Stern, H. J. (1954). Rubber: Natural and Synthetic, p. 203. Maclaren, London.

Thulliez, A. (1958). Scalpel (Brux.), 111, 1209.

Traub, E. (1946). Arch. Derm. Syph. (Chicago), 53, 205. 